\title{
Research of High-Speed Machining With Disk Cutters
}

\author{
Andrey Markov ${ }^{1, *}$, Mikhail Andreev ${ }^{1}$, Aleksey Shityuk ${ }^{1}$, and Norbert Sczygiol ${ }^{2}$ \\ ${ }^{1}$ I.I. Polzunov Altai State Technical University, 656038 Barnaul, 46 Lenin avenue, the Russian \\ Federation \\ ${ }^{2}$ Czestochova University of Technology, 21, Al.Armii Krajowej, 42-201 Czestonchowa, Poland
}

\begin{abstract}
At present, both preliminary and final HSM is recommended to be carried out according to the scheme of cut-down milling. Processing of reinforced and unreinforced polymers is also recommended to be carried out at cut-down travel. The main problem associated with cutdown milling is caused with insufficient dynamic stiffness or the presence of backlash in the feeder table. The proposed concept of machining allows eliminating fundamentally the influence of dynamic stiffness and the presence of backlash in the table feeding mechanism on the quality of machining with GUS makes it possible while retaining the advantages of cutdown milling. Some kinematic schemes for high-speed machining by milling and turnmilling are given in the paper. The schemes for forming geometrical roughness components in such machining and calculation formulas are presented. The results of experimental studies of roughness formation with disc cutters made of fiberglass composite material in high-speed machining are presented. The results obtained are compared with the calculated data.
\end{abstract}

\section{Introduction}

The task of search and introduction of technologies for processing materials in order to increase production efficiency looms are various at present. Despite the fact that $3 \mathrm{D}$ technologies have become popular recently, the essence of which is not to cut off the excess, but to build the required one, the technology of mechanical processing of materials continues to occupy a leading position in engineering production and to be improved.

High-speed machining (HSM) is one of the modern technologies with breakthrough potential. Compared with traditional methods it provides machining of a higher quality [1, 5, 7, 9], that makes possible to eliminate finishing operations. It simplifies the manufacturing process and increases the overall productivity of the products to manufacture.

\section{Description of theoretical and experimental studies}

In the works of a German engineer, Carl Salomon, who gave the first official explanation of the HSM phenomenon - High Speed Machining (patent No. 523594, April 1931, Germany), the cutting of aluminum sheets with a large-diameter disk cutter was investigated. It made 
possible to achieve high cutting speeds of up to $16500 \mathrm{~m} / \mathrm{min}(275 \mathrm{~m} / \mathrm{s})$, which are often unobtainable even with modern equipment [6]. It is obvious that K. Salomon's discovery was far ahead of its time and that is why it was not widely spread first giving way to other concepts.

Modern machine-tool industry supports HSM technology giving machine-tools special characteristics: high geometrical accuracy, high static and dynamic rigidity, temperature stability, good vibration-damping characteristics, backlash-free movement. Machines that are equipped with high-speed tool spindles with a rotational speed in the range of 12000 $40000 \mathrm{rpm}$ and more are used for HSM. The most promising are the five-axis and multipurpose machine-tools. Such equipment provides access to the workpiece from different sides at a locating and also allows flat elements to be oriented along the normal to the spindle that improves significantly the machining performance due to decrease of reinstallations and increase of machining speed.

At present, both preliminary and final HSM is recommended to be carried out according to the scheme of cut-down milling. Processing of reinforced and unreinforced polymers is also recommended to be carried out at cut-down travel. Such processing is characterized by the fact that the thickness of the chips at the entrance of the tooth to the cutting is maximum and decreases to a zero value at the exit. The cutting forces press the work piece to the machine table, thereby eliminating the possibility of elastic deformation of the part and it is easier to achieve the specified machining accuracy. But the rigidity of the equipment, fixing and the material itself must ensure the possibility of using this method of machining.

The main problem associated with cutdown milling is caused with insufficient dynamic stiffness or the presence of backlash in the feeder table. This causes vibration and, accordingly, a reduction in the quality of machining or may lead to an excessive increase in chip thickness and damage of the tool cutting edge. Some machine-tools are equipped with backlash-type gears, such as ball screws with double nuts.

The proposed concept of machining allows eliminating fundamentally the influence of dynamic stiffness and the presence of backlash in the table feeding mechanism on the quality of machining with GUS makes it possible while retaining the advantages of cutdown milling. For this purpose it is necessary at cutting speeds typical for HSM to carry out mutual movement of the tool - the disk cutter and the part during machining so that the direction of the part movement is perpendicular to the cutting speed vector, $V$. In this case, the cutting will be carried out mainly by the end face of the cutter. Fig. 1 and 2 show the kinematic schemes of high-speed milling and turn-milling that implement this concept.

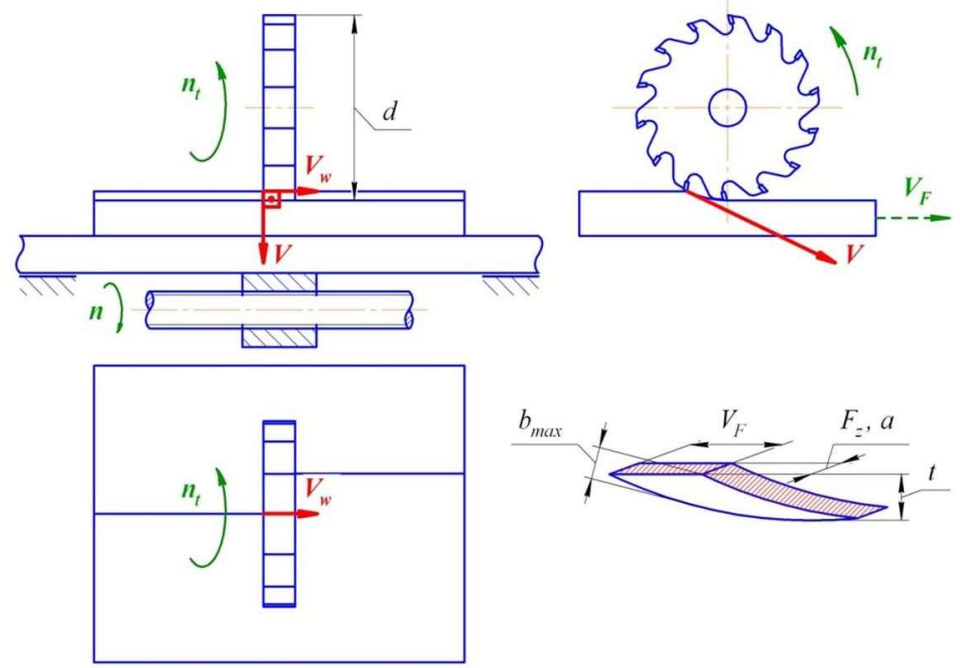


Fig. 1. Kinematic diagram of high-speed milling with disk cutters and an element of the layer cut.

High-speed milling will be performed when moving the tool - a rotating disk cutter relative to the work piece like in planning (Fig. 1). The use of a three-sided cutter as a tool will eliminate idle strokes during machining.

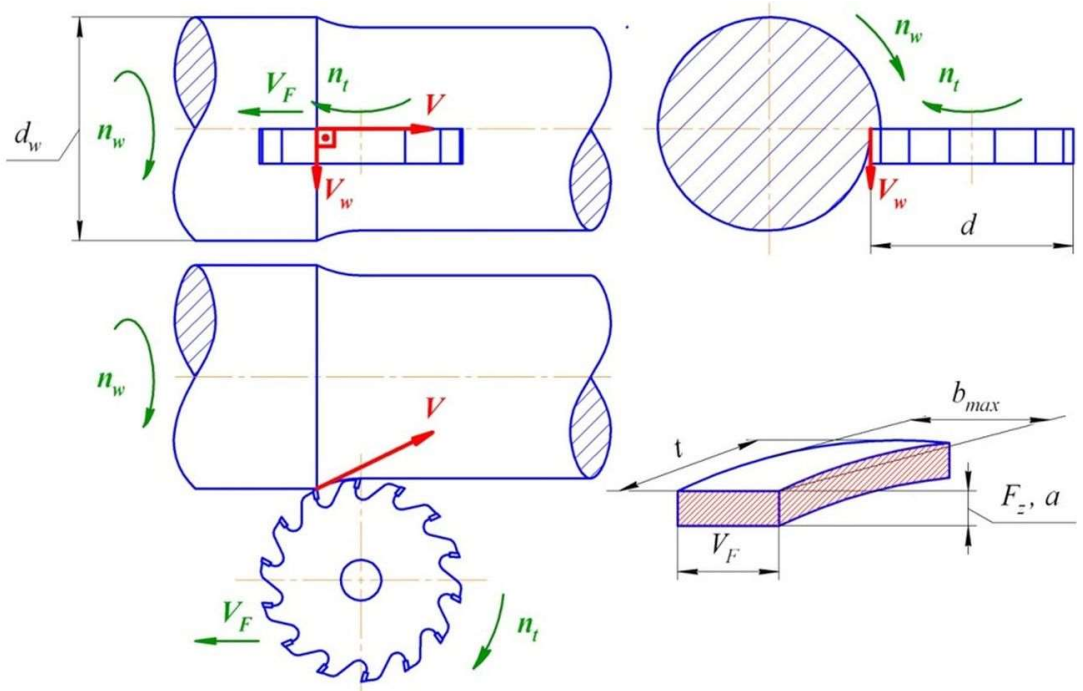

Fig. 2. Kinematic diagram of high-speed turn-milling with disk cutters and an element of the layer cut.

High-speed turn-milling will be performed when the rotating double-sided disk cutter is moved relative to the rotating part like in turning (Fig. 2). In Fig. 1 and 2 letters $a$ and $b_{\max }$ indicate the slice thickness and maximum width respectively. They are fundamentally different from the analogous parameters in traditional machining $[6,8]$.

Fig. 3 shows the formation of the geometrical components of the longitudinal roughness $h_{w}$ in high-speed milling (Fig. 3, a) and transverse roughness $h_{F}$ in high-speed milling and turn-milling (Fig. 3, b) with disk cutters.

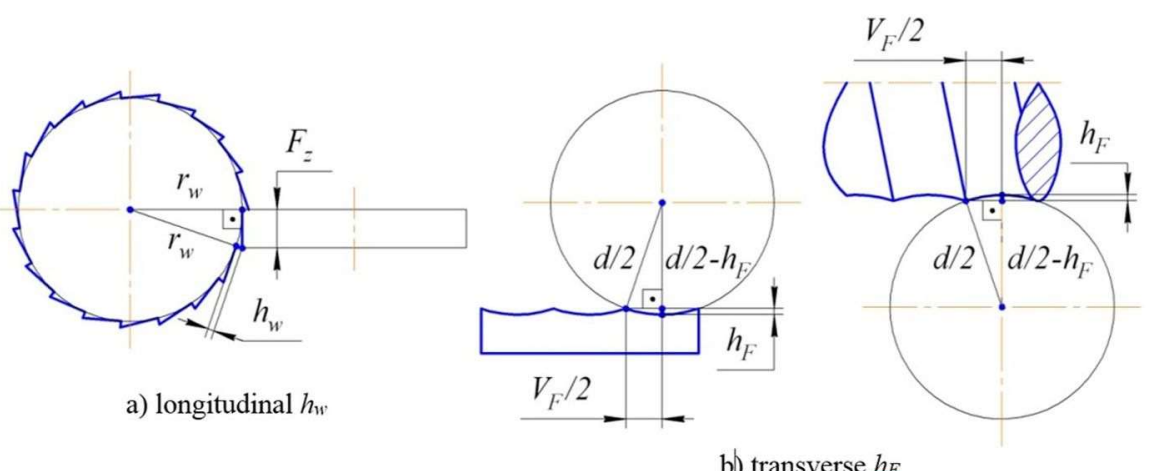

Fig. 3. Formation diagrams for the geometric components of roughness.

The Pythagorean theorem and trivial algebraic transformations make it possible to determine the geometrical components of the longitudinal and transverse roughness in highspeed machining with disk cutters $[2,11]$. 
The value of the geometrical component of the longitudinal roughness $h_{w}$ is determined as follows:

$$
\begin{aligned}
& \left(r_{w}+h_{w}\right)^{2}=r_{w}^{2}+F_{z}^{2}, \\
& r_{w}+h_{w}=\sqrt{r_{w}^{2}+F_{z}^{2}},
\end{aligned}
$$

$$
h_{w}=\sqrt{r_{w}^{2}+F_{z}^{2}}-r_{w},(\mathrm{~mm}),
$$

where $r_{w}$ - work piece radius, $\mathrm{mm}$;

$F_{z}-$ feed on a mill cutter tooth, $\mathrm{mm} /$ tooth.

The value of the geometrical component of the transversal roughness $h_{F}$ is determined as follows:

$$
\begin{aligned}
\left(\frac{d}{2}-h_{F}\right)^{2}=\left(\frac{d}{2}\right)^{2}-\left(\frac{V_{F}}{2}\right)^{2} & =\frac{d^{2}-V_{F}^{2}}{4}, \\
\frac{d}{2}-h_{F}=\frac{\sqrt{d^{2}-V_{F}^{2}}}{2}, & \\
h_{F} & =0,5 \cdot\left(d-\sqrt{d^{2}-V_{F}^{2}}\right),(\mathrm{mm}),
\end{aligned}
$$

where $d$-nominal diameter of the mill cutter, mm;

$V_{F}$ - cutter feed, $\mathrm{mm} / \mathrm{rev}$.

Experimental studies of roughness formation during high-speed machining with disc mill cutters were carried out on a composite material such as fiberglass [3, 4, 10, 12-14]. The choice of material was due to the wide use of products made of composite materials, as well as the difficulties arising in machining them by traditional methods. A fiberglass rod for insulator units of $110 \mathrm{~mm}$ in diameter that was manufactured according to SS 2296-01720994511-2010 by Biysk Fiberglass Plant LLC, Biysk, Altai territory, was to be machined.

The experiments were carried out according to the scheme of high-speed turn-milling that was the most interesting from the standpoint of roughness formation [15]. An engine lathe $16 \mathrm{~K} 20$ that was equipped with a high-speed milling head. An angle grinder UShM$180 / 1800 \mathrm{M}$ was used as a drive with a rotational speed of the circle at a nominal load of $6,500 \mathrm{rpm}$. A saw blade $180 \times 22 \mathrm{~mm} \times 40 \mathrm{~T}$ with cutting teeth made of hard alloy VK8 was used as a tool. With a nominal diameter of the saw blade $d=180 \mathrm{~mm}$ rotating with a frequency of $6500 \mathrm{rpm}$ the cutting speed was achieved:

$$
V=\frac{\pi \cdot d \cdot n_{t}}{60 \cdot 1000}=\frac{3,14 \cdot 180 \cdot 6500}{60 \cdot 1000} \approx 60(\mathrm{~m} / \mathrm{s}),
$$

where 60 is the coefficient to convert seconds to minutes;

1000 is the coefficient to convert millimeters to meters.

The speed of $60 \mathrm{~m} / \mathrm{s}$ corresponds to HSM, but during the experiments it remained constant and the effect of the cutting speed on the roughness was not found. The roughness $R a$ was monitored with a portable roughness tester TR200.

Fig. 4 shows a general view of the zone produced with a disk cutter on a specimen made of fiberglass in high-speed turn-milling. A trial experiment showed the efficiency of the proposed concept of machining.

The experiments were performed in accordance with the complete factorial experiment $(\mathrm{CFE})$ with varying factors at the following levels:

- the rotational speed $n_{w}$ of the work piece - $50 \mathrm{rpm}$ and $200 \mathrm{rpm}$; 
- feed $V_{F}$ of the rotating cutter relative to the work piece - $0.12 \mathrm{~mm} / \mathrm{rev}$ and $0.47 \mathrm{~mm} / \mathrm{rev}$

- the allowance value $t$ to the work piece radius $-0.125 \mathrm{~mm}$ and $0.25 \mathrm{~mm}$.

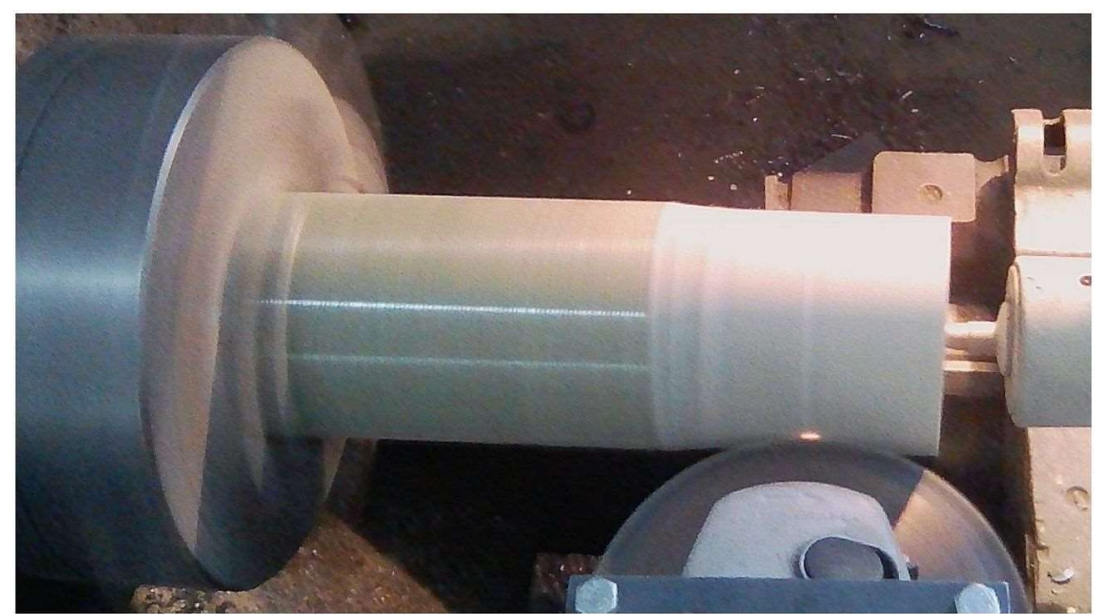

Fig. 4. General view of the zone produced with a disc cutter on a specimen made of fiberglass in high-speed turn-milling.

After statistical processing of the experimental results, a polynomial dependence of roughness on milling modes was obtained:

$$
R a=0.693+0.009 \cdot n_{w}+2.753 \cdot V_{F}+1.906 \cdot t,(\mu \mathrm{m}) .
$$

Also, a power dependence of roughness on milling modes was obtained:

$$
R a=1.050 \cdot n_{w}^{0.344} \cdot V_{F}^{0.253} \cdot t^{0.124},(\mu \mathrm{m}) .
$$

According to equation 5 it is possible to assess the influence of factors on the roughness. The rotational speed $n_{w}$ of the work piece affects the most. This is due to its influence on the amount of feed per a tooth:

$$
F_{z}=\frac{\pi \cdot d_{w} \cdot n_{w}}{z \cdot n_{t}},(\mathrm{~mm} / \text { tooth })
$$

where $d_{w}-$ the work piece diameter, mm;

$z$ - teeth number of the cutter;

$n_{t}-$ cutter rotation frequency, rev/min.

Feed per a tooth in turn, according to equation 1, affects the formation of the geometric component of the longitudinal roughness $h_{w}$.

The feed of the rotating cutter $V_{F}$ also affects the roughness, but to a lesser extent than the frequency of the work piece rotation $n_{w}$. Its influence is due to the fact that according to equation (2), it takes part in formation of the geometric component of the transverse roughness $h_{F}$.

The value of allowance $t$ affects the roughness least of all. As may be supposed this is because the value of allowance $t$ is in no way connected with the formation of the geometric roughness components.

Beyond the confines of the domain of planning CFE, one-factor experiments were performed, the graphs of which are shown in Fig. 5, 6, 7. 


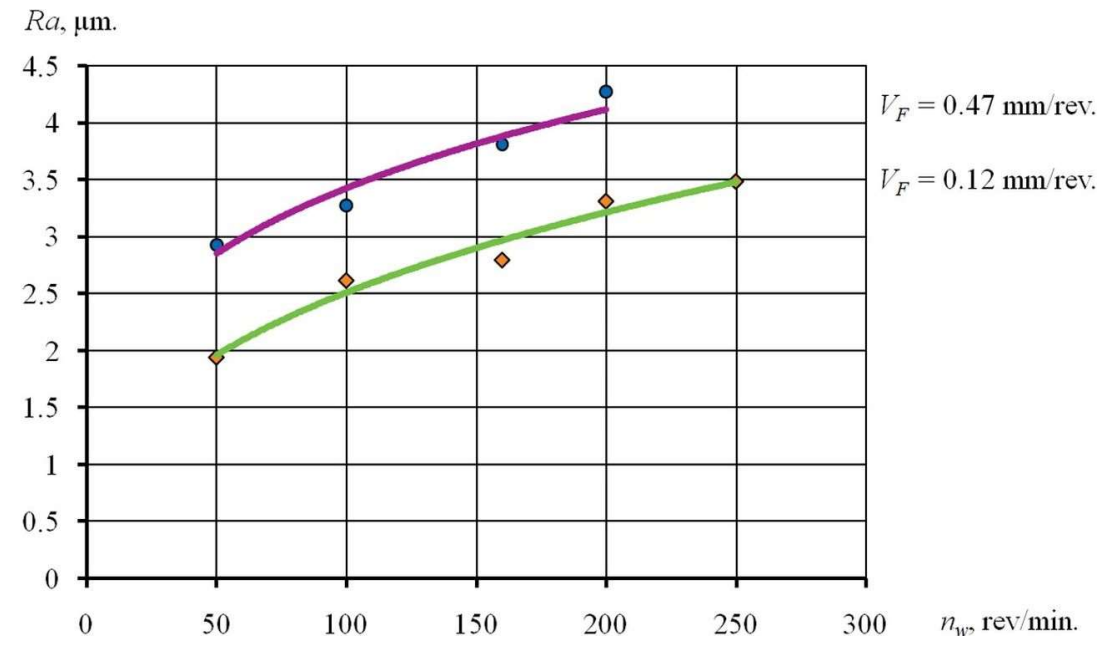

Fig. 5. The dependence of roughness $R a$ on rotation frequency of the work piece $n_{w}$ at the allowance value $0.25 \mathrm{~mm}$.

When feed of the cutter is $0.12 \mathrm{~mm} / \mathrm{rev}$ and the allowance value $t=0.25 \mathrm{~mm}$ :

$$
R a=0.484 \cdot n_{w}^{0.357},(\mu \mathrm{m}) .
$$

When feed of the cutter is $0.47 \mathrm{~mm} / \mathrm{rev}$ and the allowance value $t=0.25 \mathrm{~mm}$ :

$$
R a=1.006 \cdot n_{w}^{0.265},(\mu \mathrm{m}) .
$$

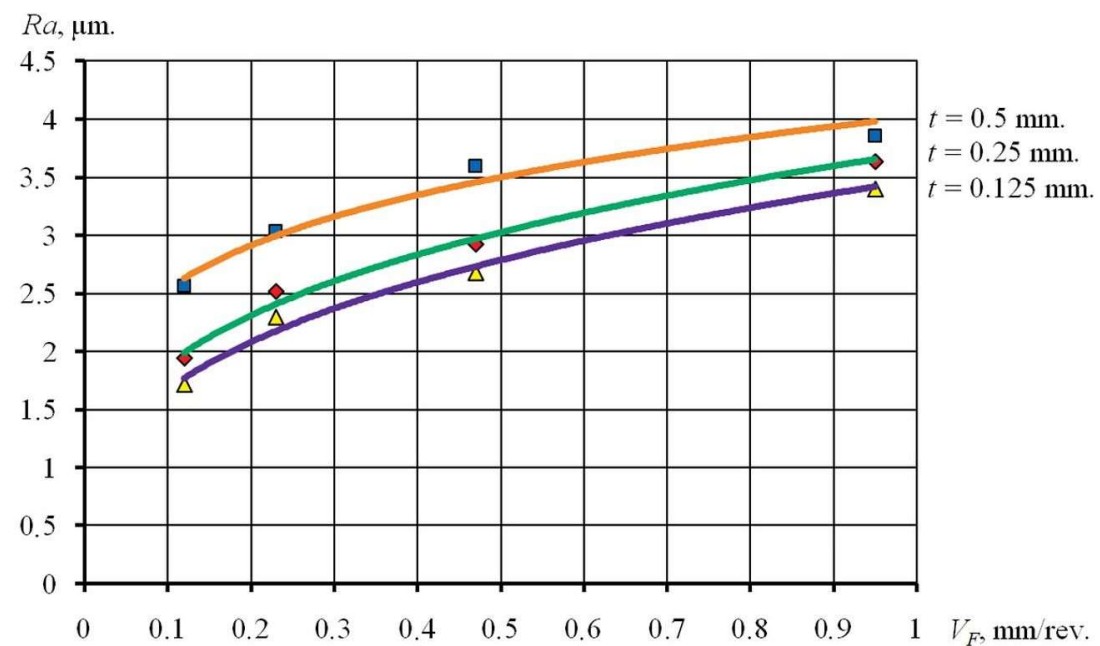

Fig. 6. The dependence of roughness $R a$ on the mill cutter feed $V_{F}$ at the rotation frequency of the workpiece $n_{w} 50 \mathrm{rpm}$.

When the allowance value is $0.125 \mathrm{~mm}$ and the rotation frequency of the workpiece $n_{w}$ 50 rpm:

$$
R a=3.472 \cdot V_{F}^{0.317},(\mu \mathrm{m}) .
$$


When the allowance value is $0.25 \mathrm{~mm}$ and the rotation frequency of the work piece $n_{w}$ 50 rpm:

$$
R a=3.704 \cdot V_{F}^{0.293},(\mu \mathrm{m}) .
$$

When the allowance value is $0.5 \mathrm{~mm}$ and the rotation frequency of the work piece $n_{w}$ $50 \mathrm{rpm}$ :

$$
R a=4.017 \cdot V_{F}^{0.200},(\mu \mathrm{m})
$$

$R a, \mu \mathrm{m}$.

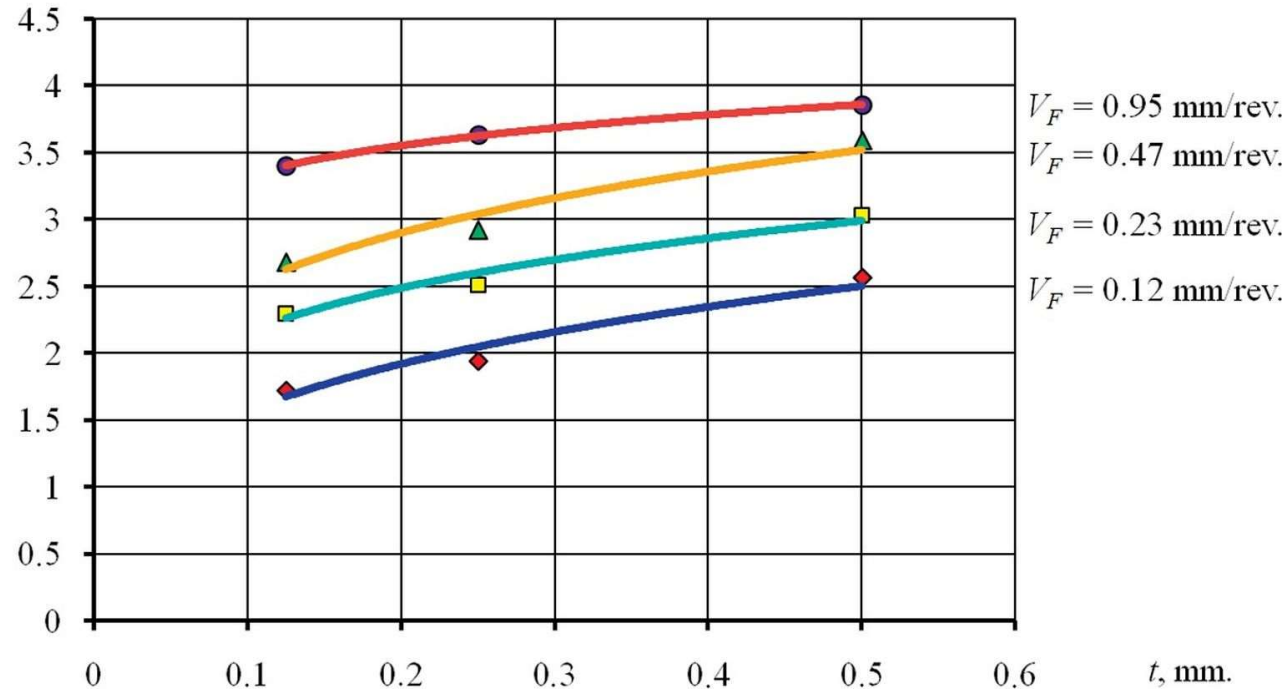

Fig. 7. The dependence of roughness $R a$ on the allowance value $t$ at the rotation frequency $n_{w} 50 \mathrm{rpm}$ of the work piece.

When the mill cutter feed $V_{F}$ is $0.12 \mathrm{~mm} / \mathrm{rev}$ and at the rotation frequency of the work piece $n_{w} 50 \mathrm{rpm}$ :

$$
R a=3.055 \cdot t^{0.290},(\mu \mathrm{m}) .
$$

When the mill cutter feed $V_{F}$ is $0.23 \mathrm{~mm} / \mathrm{rev}$ and at the rotation frequency of the work piece $n_{w} 50 \mathrm{rpm}$ :

$$
R a=3.433 \cdot t^{0.201},(\mu \mathrm{m}) .
$$

When the mill cutter feed $V_{F}$ is $0.47 \mathrm{~mm} / \mathrm{rev}$ and at the rotation frequency of the work piece $n_{w} 50 \mathrm{rpm}$ :

$$
R a=4.077 \cdot t^{0.211},(\mu \mathrm{m}) .
$$

When the mill cutter feed $V_{F}$ is $0.95 \mathrm{~mm} / \mathrm{rev}$ and at the rotation frequency of the work piece $n_{w} 50 \mathrm{rpm}$ :

$$
R a=4.111 \cdot t^{0.090},(\mu \mathrm{m}) .
$$


In general, the experiments performed showed the surface roughness deteriorates, becomes non-uniform, some grooves appear in the material being machined (Fig. 8).

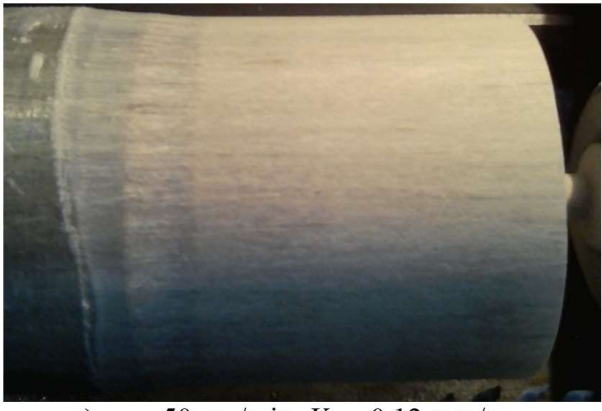

a) $n_{w}=50 \mathrm{rev} / \mathrm{min}, V_{F}=0.12 \mathrm{~mm} / \mathrm{rev}$.

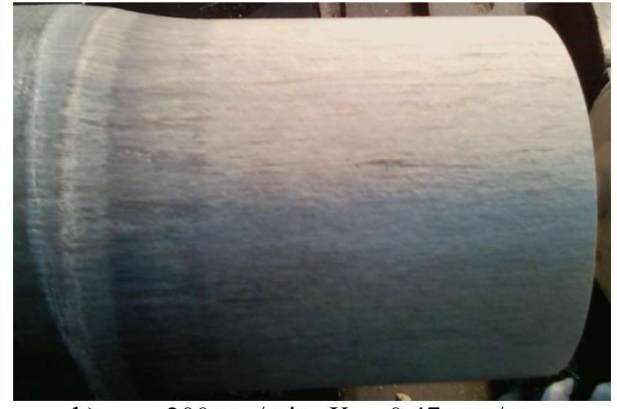

b) $n_{w}=200 \mathrm{rev} / \mathrm{min}, V_{F}=0.47 \mathrm{~mm} / \mathrm{rev}$.

Fig. 8. Surfaces of specimens made of fiberglass that were machined in high-speed turn-milling with a disk mill cutter at $t=0.25 \mathrm{~mm}$.

Therefore, like in traditional machining, rough passes should be carried out in advanced mode to ensure maximum performance. Final passes should be done in power-down mode to ensure a given surface roughness.

\section{Results and discussion}

The experiments being performed, the teeth were worn on the back surface in the form of a characteristic wear area on each second tooth. This is due to the fact that the teeth of the saw blade are alternately smoothed and only those teeth that had a one-sided bevel were involved in cutting. Consequently, the feed rate per a tooth was twice as large as the calculated value.

Comparison of the experimental results obtained with the calculated ones rejected the hypothesis that had been proposed earlier that roughness can be predicted in high-speed machining only on the basis of calculations of the geometric components of the roughness. The difference between the actual surface roughness and the algebraic sum of geometric components of the longitudinal $h_{w}$ and transverse $h_{F}$ roughness ranged from 1.3 to 11.6 times in the considered range of the CFE at various combinations of factors. The maximum discrepancy was observed at the least intense modes: rotation frequency of the work piece $n_{w}=50 \mathrm{rpm}$ and rotating cutter feed relative to the work piece $V_{F}=0.12 \mathrm{~mm} / \mathrm{rev}$. Thus, it can be assumed that the cause is not the deformation processes under the influence of cutting forces, but the anisotropy of the composite material, fiberglass.

\section{Conclusions}

The proposed way of machining is undoubtedly promising for further development and improvement due to its simplicity and accessibility. It will allow not only to use the advantages of down milling and HSM in machining parts that are traditionally machined with milling equipment, but also use the advantages of HSM for such groups of parts for which such machining was unavailable before, namely, parts like bodies of rotation. In turn, it will improve the production efficiency of the processing industry as a whole.

\section{References}

1. Eberhard, T. Emrah, M. Clemens, N. Joern, B. Enrico, F. Florian, Transactions of Nanjing University of Aeronautics and Astronautics, 4, 349 (2017)

2. A.K. Yadav, M. Kumar, V. Bajpai, N.K. Singh, R.K. Singh, Precision Engineering, 49, 287 (2017) 
3. Bandapalli, B.M. Sutaria, D.V. Bhatt, K.K. Singh, Materials Today: Proceedings, 2, 1019 (2017)

4. Bandapalli, K.K. Singh, B.M. Sutaria, D.V. Bhatt, The International Journal of Advanced Manufacturing Technology, 9:12, 2139 (2016)

5. C.F. Yao, X.T. Dou, D. Wu, Z. Zhou, J. Zhang, Advances in Mechanical Engineering, 10, $1(2016)$

6. D.A. Stephenson, J.S. Agapiou, Metal Cutting Theory and Practice, Third Edition (CRC Press, CША, 2016)

7. F. Klocke, D. Lung, M. Binder, M. Seimann, International Journal of Mechatronics and Manufacturing Systems 1:2, 3 (2015)

8. F. Xiuli, L. Wenxing, P. Yongzhi, L. Wentao, The International Journal of Advanced Manufacturing Technology, 1:4, 165 (2018)

9. H.A. Zaman, S. Sharif, M.H. Idris, D. Kurniawan, Journal of Engineering and Applied Sciences, 4, 945 (2017)

10. L. Liu, W. Wu, X. Zhu, M. Lü, Jixie Gongcheng Xuebao, 3, 196 (2015)

11. P. Kumar, V. Bajpai, R. Singh, Manufacturing Letters, 11, 12 (2017)

12. P. Thi-Hoa, M. Thi-Bich, B. Tien-Long, N. Duc-Toan, T. Van-Canh, The International Journal of Advanced Manufacturing Technology, 1-4, 177 (2018)

13. Y. Li, H.H. Zhang, J. Zhao, The International Journal of Advanced Manufacturing Technology, 1:4, 1431 (2017)

14. Y. Sun, J. Sun, J. Li, International Journal of Machining and Machinability of Materials, 3:4, 319 (2015)

15. Y.Y. Gao, J.W. Ma, Z.Y. Jia, F.J. Wang, L.K. Si, D.N. Song, The International Journal of Advanced Manufacturing Technology 9:12, 1757 (2016) 